\title{
Diretrizes Metodológicas: Elaboração de Diretrizes Clínicas
}

\author{
Methodological Guidelines: Elaborating Clinical Guidelines
}

Directrices Metodológicas: Elaboración de Directrices de Práctica Clínica

\author{
Ministério da Saúde. Secretaria de Ciência, Tecnologia e Insumos Estratégicos. \\ Departamento de Gestão e Incorporação de Tecnologias em Saúde. Diretrizes \\ metodológicas: elaboração de diretrizes clínicas. Brasília: Ministério da Saúde; 2016. \\ ISBN: 978-85-334-2372-5
}

Camila Belo Tavares Ferreira ${ }^{1}$

Da série de publicaçôes sobre metodologias utilizadas nos processos de avaliação tecnológica no Brasil, a mais recente é intitulada Diretrizes Metodológicas: Elaboração de Diretrizes Clínicas.

Diretrizes clínicas baseadas em evidências contêm recomendaçóes sobre as intervenções que demonstram segurança, eficácia e efetividade, acompanhadas da avaliação dos benefícios e possíveis danos à saúde da população. Esses documentos são elaborados com base em revisôes sistemáticas da literatura com qualidade avaliada, em resposta às perguntas relevantes oriundas da prática de atenção à saúde.

Sendo assim, um manual torna-se relevante no Sistema Único de Saúde (SUS) uma vez que a há necessidade de orientar a elaboração e padronizar os formatos apresentados de diretrizes e protocolos clínicos e terapêuticos de acordo com os critérios estabelecidos pela Comissão Nacional de Incorporação de Tecnologias no SUS (Conitec).

O processo de elaboraçáo de diretrizes clínicas e protocolos terapêuticos pelo Instituto Nacional de Câncer José Alencar Gomes da Silva (INCA) vem evoluindo, acompanhando a tendência das principais agências internacionais de avaliação de tecnologias em saúde. A proposta de elaboração de um guia para produção desse documento surgiu da experiência com o desenvolvimento metodológico das Diretrizes de Detecçáo Precoce do Câncer de Mama no Brasil e a necessidade de reportar as etapas e as recomendaçôes internacionais sobre o processo.

A produção e a revisão técnica do manual foram conduzidas por equipe multiprofissional e interinstitucional, composta por técnicos do INCA, do Instituto Nacional de Cardiologia (INC)/Conitec, da Universidade Federal do Rio de Janeiro (UFRJ) e da Universidade Federal de Ciências da Saúde de Porto Alegre (UFCSPA).

A publicação, dirigida aos profissionais de saúde, gestores e demais técnicos envolvidos em diretrizes clínicas, contempla em seus capítulos as principais etapas incluídas para sua elaboração, identifica as estratégias de difusão, disseminação e implementação, bem como orienta sobre os mecanismos de avaliação da qualidade de diretrizes.

Na prática, o manual ou "Guia das Guias" subsidia as áreas técnicas do Ministério da Saúde que apresentarão à Conitec necessidade de atualização, adaptação e elaboração de diretrizes e protocolos clínicos baseados em evidências. O processo descrito e contextualizado pela diretriz metodológica está em acordo com a Portaria $\mathrm{n}^{\circ} .27$, de 12 de junho de 2015, que estabelece o fluxo de trabalho dessas publicaçóes no âmbito da Conitec.

Além do próprio Ministério da Saúde, o guia pode ser ainda utilizado por outras entidades que produzem diretrizes e protocolos clínicos locais, na falta de diretrizes nacionais, contribuindo para a qualificação técnico-científica de profissionais e instituiçôes envolvidas no campo da avaliação tecnológica em saúde (ATS).

Cabe ressaltar as mudanças ocorridas na elaboração de diretrizes uma vez que, geralmente, as recomendações eram apresentadas por meio de Consensos em que os especialistas selecionavam estudos sem um critério explícito

${ }^{1}$ Bibliotecária. Mestre em Ciência da Informação e Tecnologista em Ciência e Tecnologia do Instituto Nacional de Câncer José Alencar Gomes da Silva (INCA). Supervisora do Sistema Integrado de Bibliotecas do INCA. Membro do Núcleo de Avaliação de Tecnologias em Saúde (NATS)/INCA. E-mail: camila.ferreira@inca.gov.br. 
ou avaliação de qualidade. Assim, um instrumento que norteie sobre as etapas a serem cumpridas de acordo com as orientaçôes técnicas vigentes, aliadas às outras estratégias de capacitação de recursos humanos, aponta para um cenário de otimização dos cuidados de saúde prestados à população.

Considerando o conjunto de competências e habilidades necessárias para execuçáo desse trabalho, o manual recomenda uma equipe multiprofissional com experiência tanto no método (epidemiologistas, bibliotecários, especialistas em ATS) quanto no escopo das diretrizes. O conjunto de conhecimentos e ferramentas necessárias para alinhar evidências, valores e preferências da população é fundamental para construção de diretrizes e protocolos clínicos. Nesse sentindo, com papéis bem delineados, a equipe do projeto deve integrar a gestão da informação e gestão estratégica para adequada síntese das evidências com foco na sua implementaçáo. No que se refere à gestão da informação, a busca de evidências deve considerar, preferencialmente, estratégias sensíveis para recuperação de revisões sistemáticas publicadas e indexadas em múltiplas fontes de informação.

Destaca-se a importância do tempo necessário para o desenvolvimento de todas as etapas. Com o rigor metodológico preconizado, o dimensionamento do escopo, o número de perguntas e a quantidade de técnicos envolvidos, a elaboração de uma diretriz baseada em evidências pode durar até 12 meses. Vale lembrar que, nesse cronograma, o investimento de tempo com a elaboração do escopo e da busca de evidências são fundamentais, já que muitos tendem a abreviar essas etapas causando grandes prejuízos nos resultados.

Entende-se como uma das vantagens do manual pertencer a uma série sobre metodologias inerentes à ATS. Dessa forma, não há necessidade de esgotar ou aprofundar determinados tópicos já detalhados em outros títulos da série, devidamente citados, como adaptaçáo de diretrizes e o sistema GRADE. Além disso, a publicação mostra o passo-a-passo da metodologia e conta com sete apêndices incluindo modelos, instrumentos, links úteis para busca de evidências e referências relevantes sobre o tema. 